\title{
OPTIC NEURITIS IN SECOND EYE FOLLOWING PERFORATING WOUND AND EXCISION
}

\author{
BY \\ Frank W. LAW \\ SENIOR HOUSE SURGEON, MOORFIELDS EYE HOSPITAL
}

THE two cases recorded below appear to me to be of sufficient interest to deserve publication.

Case 1. R. S. Male, aged 20 years. On June 22, 1927, this patient sustained a perforating wound of the right eye from a piece of vulcanite. There was an irregular wound of the centre of the cornea to which the iris was adherent, though there was no actual prolapse ; the lens was grossly injured, only a dull temporal reflex being obtained; vision was reduced to counting fingers at 12 inches. The left eye was normal, with vision $6 / 6$ and J.1. On the 30 th the synechia was divided; curette evacuation was performed on July 7; the synechia was again divided on July 28 and August 11-in every case but the last there was still some remaining adhesion of iris to cornea. On August 23 there was considerable ciliary injection, with oedema of lids; the iris was free but discoloured; there were no keratic precipitates nor aqueous flare, but some endothelial bedewing was present. There was no red reflex, and the tension was low. The left eye was normal, and the differential white count also normal. It was, however, decided to excise the right eye; this was done on September 6 , and the patient was discharged on the 10th; the left vision was then $6 / 9$ partly, improved to $6 / 5$ with a horizontal cylinder of $-0.75 \mathrm{D}$.

On November 3 the patient complained of slight pain in the left eye; vision was $6 / 6$ unaided. Nothing further of note occurred until August 9, 1928, when he complained of blurred vision in the eye; vision was then found to be $6 / 12$ unaided, improved to $6 / 6$ pt. with $\frac{+0.75 \text { D.Sph. }}{+0.75 \text { D.Cyl. } 100^{\circ}}$. This correction was ordered.

On November 5 the patient was sent up to Hospital by his doctor on account of poor vision :- it was then found to be $6 / 36$ with his glass, and not improved. Nothing abnormal was revealed on examination of the eye. The patient gave a history of severe nasal catarrh one month previously, but complained of no pain in the eye. On November 8 slight blurring of the disc was noticed, with a questionable pallor on the temporal side; there was also a suggestion of facial Parkinsonianism. Neurological examination revealed no extra-ocular cause, and a course of potassium iodide was advised; the urine was normal. The ear, nose, and throat report was to the effect that the tonsils were red; the nose was free from pus, which was, however, present in the post-nasal space; 
a swab revealed the presence of M. Catarrhalis, S. Aureus, and Pneumo-bacilli. X-ray examination showed that the sinuses were clear, the nasal septum deflected, and the turbinates sufficiently enlarged to cause obstruction. Tonsillectomy was recommended, and a gargle and paint ordered. The Wassermann reaction was negative.

The patient was readmitted to hospital on December 1. Careful enquiry after other symptoms elicited nothing except a possible slight increase during the last 3 months of the patient's customary stammer. The eye showed no gross change; the pupillary reaction was ill-sustained, and a condition of hippus was present. The slight lack of definition of the disc, with temporal pallor, was still noticeable; the vessels appeared normal. Vision was $6 / 36$ pt., not improved, and J.4 at 6 inches-refraction was +1.25 horizontal, +0.75 vertical. The visual field was full, and the blind spot normal; there was a small central scotoma for red and green. On December 4 the neurologist's report gave no suggestion of early disseminated sclerosis; on December 13 an X-ray photograph of the skull was taken, which revealed no abnormality of skull, nor of sella Turcica in particular. Faint evidence of connective tissue along the vessels near the disc was noted on January 1,1929 .

There was no improvement in the vision as a result of in-patient treatment, which included atropine, local heat, hot-air baths, mercury, and iodides, with intramuscular milk injections; the patient was discharged on January 2 , when the visual acuity with a +1.5 D.Sph. was only sufficient to enable him to count fingers at 2 metres.

Case 2. I. S. Female, aged 16 years. The perforating wound in this case was to the left eye, and was caused by a knife held in the patient's hand. It extended from a point half-way out on the cornea, at 4 o'clock, horizontally inwards to a point $4 \mathrm{~mm}$. outside the limbus; ciliary body and lens were involved, and the iris was torn and prolapsed. The case was admitted on the day of the accident, May 25, 1928, and the eye excised on the 30th. Convalescence was uneventful, and on discharge on June 4 the right eye was normal, vision being $6 / 6$ partly, unaided, and $6 / 6$ all with a $+1.0 \mathrm{D} . \mathrm{Sph}$.

The girl attended regularly as an out-patient, and nothing of note occurred until October 13 when she complained of pain in the right eye of one week's duration, with mistiness of vision for one day. She was readmitted to hospital, and on close enquiry it was found that she had suffered from headaches ever since she had left hospital, and had vomited on the day before readmission. There was still some pain in the right eye, especially on movement; on examination all but the fundus was normal. The optic disc was swollen to 3D., the margins were blurred, and there was some circumpapillary retinal oedema. All the arteries were constricted 
near the disc, attaining their normal size peripherally; the lower branch of the central artery pulsated on pressure, while the upper did not; the veins were all engorged with the exception of the superior nasal. There were no haemorrhages, and the macula was normal. Central vision was poor, especially for colours, and was reduced to counting fingers at 12 inches; with a $+5.0 \mathrm{D}$.Sph., fingers were counted at 1 metre; projection was accurate. The field of vision was full, and the blind spot showed only slight horizontal enlargement. No extraocular disease was found by the neurological and other departments, with the exception that there was some pyorrhoea; the mouth was, however, satisfactory after scaling and treatment.

Treatment consisted in local dry heat, and hot air baths, atropine, and iodides. The patient complained of right earache on the 16th which responded to simple treatment.

On the 22nd there was less swelling of the disc, and all the vessels pulsated on pressure; fingers were counted at 2 feet (unaided). On the 31st there was no measurable swelling, and vision, with the aid now of a $+6.0 \mathrm{D}$.S. had improved to $6 / 9$. The patient was discharged on December 7 to a Convalescent Home, vision being still as above; there was slight pallor of the disc, with blurring of its margins. On her return on December 27 vision was still $6 / 9$; the disc appeared normal, and the visual field was full. No change has since been noted.

The possibility of the involvement of the second eye being pure coincidence in each of the above cases must be at once admitted: but in case this were not so, it would be of considerable interest if these notes brought to light any similar cases hitherto unrecorded.

I am indebted to the honorary surgeons concerned, Sir John Parsons and Mr. Frank Juler, for their permission to report these cases.

NOTE ON THE CONTINUOUS EMPLOYMENT OVER A PERIOD OF YEARS OF SOLID ATROPINE AND COCAINE FOR CHILDREN'S REFRACTION

BY

\section{ERNEST THOMSON}

STIRLING

THE continuous employment of one method of doing anything, over a period of years and a large number of cases, furnishes not only a mass of statistics if one cares to extract these, but also gives a general impression of the value of the method, which is perhaps even more useful than bald figures. During the fourteen years 